ARTIGO

\title{
A MATRÍCULA COMO DIREITO DO ESTUDANTE NA PANDEMIA DA COVID-19
}

\author{
ENROLLMENT AS A STUDENT'S RIGHT IN THE COVID-19 PANDEMIC
}

LA MATRÍCULA COMO DERECHO DEL ESTUDIANTE EN LA PANDEMIA COVID-

\author{
Ester Maria de Figueiredo Souza \\ Universidade Estadual do Sudoeste da Bahia - Brasil \\ Lúcia Gracia Ferreira \\ Universidade Federal do Recôncavo da Bahia - Brasil \\ Universidade Estadual do Sudoeste da Bahia - Brasil
}

\begin{abstract}
Resumo: Este texto aborda o direto à matrícula escolar com a escolaridade nos tempos de pandemia do novo coronavírus. Parte do princípio de que a matrícula escolar é lastreada pelo direito à educação, conforme se preconiza na Constituição da República Federativa do Brasil (1988), simbolizando a validação da identidade estudantil. Para tanto, referencia-se nas normativas e leis que regem o ordenamento jurídico brasileiro para cotejar informações de domínio público e apresentam-se o ensino emergencial e mapeamento da situação de oferta da educação no país, expondo estratégias para validar o ano letivo, como também alternativas para terminalidade de estudos. Desse modo, se configurou como uma pesquisa qualitativa, exploratória e documental que reúne conjunto de dados relevantes para contexto e problematizacão do percurso do estudante. Constata-se que a pandemia atingiu o direito a matrícula, em maior escala nos estabelecimentos públicos de ensino e que foi protelada, por circunstâncias impostas pela COVID-19, a tomada de decisão para validar esse direito.
\end{abstract}

Palavras-chave: COVID-19. Direito Educacional. Ensino Remoto. Matrícula escolar.

\begin{abstract}
This text addresses the right to school enrollment in the pandemic times of the new coronavirus. It starts from the principle that school enrollment is supported by the right to education, as advocated in the Constitution of the Federative Republic of Brazil (1988), symbolizing the student identity validation. For this purpose, it is referenced the norms and laws that govern the Brazilian legal system to analyze information in the public domain and also emergency education and mapping the situation of education provision in the country are presented, exposing strategies to validate the school year, as well as alternatives to ending the studies. In this way, it was configured as a qualitative, exploratory and documentary research that gathers a set of relevant data for context and problematization of the student's path. We found that the pandemic reached the right to enroll, on a larger scale in public educational establishments, and that decision-making to validate this right was postponed, due to circumstances imposed by COVID- 19 .
\end{abstract}

Keywords: COVID-19. Educational Law. Remote Teaching. School enrollment. 
Resumen: Este texto aborda el derecho a la matrícula escolar con la escolarización en tiempos de pandemia del nuevo coronavirus. Se parte del principio de que la matrícula escolar se sustenta en el derecho a la educación, tal como lo preconiza la Constitución de la República Federativa de Brasil (1988), que simboliza la validación de la identidad del estudiante. Por lo tanto, se hace referencia a las normas y leyes que rigen el ordenamiento jurídico brasileño para analizar información de dominio público y se presenta educación de emergencia y mapeo de la situación de la oferta educativa en el país, exponiendo estrategias para validar el año escolar, así como alternativas para finalización de estudios. De esta manera, se configuró como una investigación cualitativa, exploratoria y documental que recoge un conjunto de datos relevantes para el contexto y problematización del camino del estudiante. Encontramos que la pandemia alcanzó el derecho a matricularse, en mayor escala en los establecimientos educativos públicos, y que, por circunstancias impuestas por COVID-19, se pospuso la toma de decisiones para convalidar este derecho.

Palabras clave: COVID-19. Ley Educativa. Enseñanza remota. Matrícula escolar.

\section{Considerações Iniciais}

A oferta da educação, como direito, é dependente de políticas públicas educacionais sustentadas pelo Estado e para o âmbito privado, por delegação de atendimento. A educação é um direito social inalienável definido pela Constituição da República Federativa do Brasil (CRFB) de1988 e teve na Lei de Diretrizes e Bases da Educação Nacional nº 9.394/96 (LDB) o respaldo para seu ordenamento no território brasileiro.

No findar do ano de 2020, tivemos a aprovação do novo Fundo de manutenção e Desenvolvimento da Educação Básica (FUNDEB) - e esse fato assenta uma conquista histórica para a educação brasileira, visto que a terminalidade da vigência do Fundo educacional deixou de ser condicionada. Em linhas breves, a Proposta de Emenda Constitucional n ${ }^{\circ} 15$ apresentada em 2015, somente em 2020 foi sancionada pelo Congresso Nacional como a Emenda Constitucional $\mathrm{n}^{\circ} 108$ e, no rito legislativo, após árdua defesa dos grupos progressistas da sociedade civil, do Congresso Nacional e das entidades de classe e foi regulamentada pela Lei $\mathrm{n}^{\mathrm{o}}$ 14.113, de 25 de dezembro de 2020, que regulamenta o Fundo de Manutenção e Desenvolvimento da Educação Básica e de Valorização dos Profissionais da Educação. ${ }^{1}$

Esse fato histórico tem relevada importância, visto que o condicionamento da terminalidade do Fundo deixa de existir, tornando-o permanente, bem como amplia o percentual de recursos da União de $10 \%$ para $23 \%$ a ser integralizado até o ano de 2026, garantindo inegável equalização de oportunidades educacionais.

De forma especial, destaca-se a matrícula escolar, vez que a composição dos recursos orçamentários, na sua distribuição, toma como uma das referências o indicador de matrícula na

\footnotetext{
${ }^{1}$ Brasil (2020a), em https://www.in.gov.br/en/web/dou/-/lei-n-14.113-de-25-de-dezembro-de-2020-296390151.
} 
educação básica, nos níveis da educação infantil, ensino fundamental e ensino médio e, desde a Constituição cidadã, como ficou conhecida a Constituição de 1988, em seu artigo 208, o dever do Estado com a educação deve ser efetivada mediante a garantia de oferta gratuita, universalização, atendimento com qualidade, dentre outras obrigações.

Esse direito à educação, materializa-se na validação da matrícula e desde a vigência da CRFB e da LDB marcos jurídicos foram incorporados, avançado o início da obrigatoriedade da matrícula escolar para os 4 anos, o que explanaremos em seção deste texto.

Quando da decretação do Estado de Emergência de Saúde Pública de Importância Internacional em decorrência do novo coronavírus (SARS-COV-2 ${ }^{2}$ ), em 2020, pela Organização Mundial de Saúde (OMS), o sistema de ensino do Brasil já havia operacionalizado, por meio de seus Estados e Municípios, a matrícula escolar de estudantes já pertencentes à rede de ensino e, em grande número, novas matrículas foram acolhidas. A garantia de um direito social como a educação exige a adoção de medidas governamentais e a constante participação da sociedade civil organizada, o que foi possível de se constatar por meio das normativas expedidas pelos órgãos reguladores. Contudo, a impossibilidade de garantir condições materiais de acesso e adoção de medidas sanitárias também atingiu o atendimento desse direito. É nesse intuito de relacionar o direto à matrícula escolar com a garantia da oferta da escolaridade nos tempos de pandemia que refletiremos neste trabalho.

Neste texto, portanto, cotejamos informações de domínio público, sendo normativas publicadas pelo Conselhos Nacional de Educação (CNE) e Estaduais, na Lei n ${ }^{\circ}$ 9.394/96 (LDB), Constituição da República Federativa do Brasil, decretos, resoluções e outras legislações para explanar o tema em estudo, ou seja, a matrícula como direito do estudante na pandemia da COVID-19. Desse modo, o artigo apresentado deu-se a partir de uma pesquisa qualitativa, exploratória e documental, realizada no ano de 2020.

\section{A matrícula como expressão de cidadania da criança, adolescente e jovem estudante}

É dever do Estado garantir a educação básica obrigatória e gratuita. Essa obrigatoriedade adveio com a Emenda Constitucional n ${ }^{\circ} .59 / 2009$, que alterou a redação do inciso I do art. 208 da Constituição Federal. Novas orientações sobre matrículas foram estabelecidas pela Lei ${ }^{\circ}$ 12.796/2013, que altera a LDB de 1996, tornando obrigatória a oferta gratuita de educação

\footnotetext{
${ }^{2}$ Esse vírus provoca a doença COVID-19.
} 
básica a partir dos 4 anos de idade, sendo, em seu artigo $6^{\circ}$ dever dos pais ou responsáveis efetuar a matrícula das crianças na educação básica a partir desse corte etário.

O direito à educação, nas palavras de Arroyo (2004) é tomado:

[...] como direito à formação e ao desenvolvimento humano, como humanização, como processo de apropriação das criações, saberes, conhecimentos, sistemas de símbolos, ciências, artes, memória, identidades, valores, culturas... resultantes do desenvolvimento da humanidade em todos os seus aspectos (ARROYO, 2004, p. 12).

Desse modo, como direito deve atender, de modo igualitário, toda a sociedade, proporcionando viabilidades para que todos se desenvolvam. A formação humana, tomada como tema central na perspectiva do direito, tem relação com o desenvolvimento humano que devem se configurar como um conjunto de possibilidades que se relacionam a vida em sociedade.

A LBD disciplina a organização da Educação Brasileira em a) educação infantil, sendo creche para crianças de até 3 anos de idade e pré-escola para crianças de quatro à cinco anos de idade; b) ensino fundamental a partir dos 6 anos; e, c) ensino médio. Destaca-se que para o segmento de creche não há obrigatoriedade das matrículas pelos responsáveis pela criança, exigindo-se, por usa vez, a obrigatoriedade da oferta da vaga pelo ente federativo que goza dessa prerrogativa, no caso, o município.

A partir dos quatro anos de idade, completados em março do ano letivo, a criança ao se matricular no estabelecimento de ensino, público ou privado, amplia o lastro de sua cidadania, sendo reconhecido como um sujeito de direitos, como preconiza Arroyo (2004). Desse modo, a escolarização, que inicia com a matrícula, é um modo de garantia desses direitos.

Com a sanção da Lei $n^{\circ}$. 11.114, de 16 de maio de 2005 (BRASIL, 2005³), torna-se obrigatória a matrícula das crianças de 6 anos de idade no Ensino Fundamental. Essa lei impacta na organização do ensino fundamental, visto que anteriormente esse era organizado em oito anos. Assim, em decorrência, a Lei n. 11.274, de 6 de fevereiro de 2006 (BRASIL, 2006), ao ampliar o ensino Fundamental para nove anos de duração, com a exigência de matrícula de crianças de 6 anos de idade redireciona aos órgãos gestores atentar para a garantia do fluxo escolar da educação infantil para a etapa seguinte, além de elaboração de propostas pedagógicas que se vinculem a políticas públicas de educação.

\footnotetext{
${ }^{3}$ Altera os arts. $6^{\circ}, 30,32$ e 87 da Lei no 9.394 , de 20 de dezembro de 1996, com o objetivo de tornar obrigatório o início do ensino fundamental aos seis anos de idade.
} 
A obrigação da matrícula também é disciplinada no art. 55 do Estatuto da Criança e do Adolescente/ECA, Lei 8.069/1990), conforme disposto no art. 22 (Art. 53 do Estatuto da Criança e do Adolescente - Lei 8069/90). O ECA ressalta que:

Art. 22. Aos pais incumbe o dever de sustento, guarda e educação dos filhos menores $[\ldots]$

Art. 55. Os pais ou responsável têm a obrigação de matricular seus filhos ou pupilos na rede regular de ensino.

Nessa perspectiva, além de ser dever do Estado e da família, como preconiza a CRFB, é obrigação legal dos pais ou responsáveis a realização da matrícula. Esta que é a expressão primeira de possibilidade de escolarização, ou seja, do direito à educação.

Estudantes são sujeitos de direito ao conhecimento escolar, e, assim, o ingresso e continuidade em uma instituição escolar é condição para que esse se encontre com o currículo, pois:

[...] guiados pelo imperativo ético do respeito aos educandos, como sujeitos iguais de direitos, seremos levados a construir novas formas de ordenamento dos conteúdos que garantam não apenas o direito igual de todos ao conhecimento, à cultura, aos valores, à memória e à identidade na diversidade, mas que garantam a igualdade de todo conhecimento, cultura, valores, memórias e identidades sem hierarquias, segmentações e silenciamentos. [...]. Ainda, guiados pelo imperativo ético do respeito aos educandos, como sujeitos iguais de direitos, seremos obrigados a reconhecer que o direito à educação, ao conhecimento, à cultura e à formação de identidades não se dá isolado do reconhecimento e da garantia do conjunto dos direitos humanos. (ARROYO, 2004, p. 38).

Ser sujeito de direitos significa ser um sujeito com garantias legais. A educação, aqui no caso em discussão, não deve ser só garantida através da matrícula, acesso e permanência na escola, mas também pela qualidade do ensino, as igualdades de oportunidades, a igualdade de acesso ao conhecimento e aos bens culturais etc. Nessa prerrogativa ainda se encontram os direitos fundamentais, aqueles que garantem a convivência digna, diversa, livre e igual de todas as pessoas, sem os quais não convivemos, não nos realizamos e, muitas vezes, não sobrevivem.

O acesso e a permanência se configuram como uma expressão segunda (seguida da matrícula) para concretização desse direito a educação. Os estudantes precisam ter condições para permanecerem na escola e CRFB (BRASIL, 1988), estabelece no artigo 206 que "O ensino será ministrado com base nos seguintes princípios: I - igualdade de condições para o acesso e permanência na escola”. Esse princípio se refere a condução do ensino e é retificado pelo ECA no artigo 53: "A criança e o adolescente têm direito à educação, visando ao pleno desenvolvimento de sua pessoa, preparo para o exercício da cidadania e qualificação para o 
trabalho, assegurando-se lhes: I - igualdade de condições para o acesso e permanência na escola".

A educação é necessária para promoção do desenvolvimento social e pessoal das pessoas, inclusive como exercício da cidadania. O acesso e a permanência à escola deve ser um processo democrático que pressupõe a universalização da educação básica ${ }^{4}$. Esta possibilita a escolarização que dá acesso a conhecimentos e a construção destes; também, para além disso, deve promover o bem-estar do cidadão para convivência entre os pares e aprendizagens coletiva. Estes colaboram, são inclusive condições sine qua non, para construção de uma sociedade democrática, e a universalização citada é expressão de justiça social ${ }^{5}$, quando, principalmente, atende o direito a matrícula, ao acesso e a permanência de crianças e adolescentes nas escolas. Tudo isso são garantias do direito a educação.

No cenário da Pandemia da COVID-19, que se iniciou no ano de 2020, matrícula escolar ficou comprometida neste ano e no subsequente, visto a dependência de conclusão de ano escolar, o que não foi possível devido a suspensão das aulas e não cumprimento do calendário letivo. Uma questão se impõe: qual o desafio de matricular os filhos na escola pública durante a pandemia? Este é o tema de uma reportagem do site Desafios da Educação que traz o depoimento de três mães sobre essa situação. Dessa forma, Pujol (2020, s/p) descreve que:

É o caso de Débora Regina Moraes, moradora do bairro de Campo Grande, no Rio de Janeiro (RJ).

Com a crise econômica potencializada pela pandemia, ela ficou desempregada e sem condições de pagar as mensalidades da filha, matriculada em uma escola particular do Rio. A saída foi matricular a filha em uma escola pública municipal. Mas encontrou dificuldades. "Tentei uma vaga na rede pública e não consegui." (grifo nosso).

A situação se repete no interior do estado. Kecya Rodrigues da Silva, também desempregada, tem duas filhas matriculadas em uma escola privada na Baixada Fluminense. Ela pretende inscrever as meninas em uma escola da rede estadual. "Mas o site do governo diz que, no momento da pandemia, as matriculas estão suspensas." (grifo nosso).

É o caso de C., que não quis se identificar. Ela é de Ouro Branco (MG) e está disposta a tirar os filhos de 6 e 9 anos da escola particular. "Durante a pandemia, a renda da nossa família diminuiu muito", justifica.

"Porém, quando procuro a secretaria de educação da minha cidade, dizem que não estão autorizados a fazer matrículas. Então liguei para a Superintendência Regional de Ensino (SRE) que, por causa da pandemia, informou que não tem ninguém para me atender. Como resolvo isso?" (grifo nosso).

\footnotetext{
${ }^{4}$ Sobre a universalização da educação básica ver pesquisa de Trevisol e Mazzioni (2018).

${ }^{5}$ Sobre a perspectiva de justiça social ver Azevedo (2013) e Pizzio (2016).
} 
Desse modo, as dificuldades sinalizadas são decorrentes da crise instalada devido à pandemia. Na verdade, não estávamos preparados para isso. As Secretarias de Educação não estavam preparadas para os impactos de tamanha proporção como os que vem ocorrendo neste momento.

Como já sinalizamos a matrícula é um direito, portanto, deve ser efetivada. No entanto, conforme esses depoimentos, este vem sendo procrastinado. Na mesma reportagem, Salomão Ximenes, professor da Universidade Federal do ABC, remete ao desafio imposto pela pandemia, aos sistemas de matricula da rede pública, mas não acha justificáveis as ocorrências quanto as dificuldades para se fazer a matrícula. Aponta que "seria razoável um governo levar 20 dias ou um mês para reorganizar o sistema de cadastro. Mas três meses sem uma solução é difícil de compreender". Ainda que, "a educação é um direito universal. Portanto, obrigação do Estado - que deveria ter adaptado uma resposta administrativa ao contexto da covid-19" (PUJOL, 2020, s/p).

As dificuldades para consolidação do direito à matrícula estão relacionadas a problemas de gestão, falta de estrutura para lidar com o sistema de matrículas, organização e planejamento. Ainda, perpassa pela falta de um compromisso político com a educação e de um comprometimento com o processo de transformação social (FREIRE, 1999, 2003, 2018).

Como já informado, no cenário brasileiro, encontramo-nos, desde 18 de março de 2020, conforme Decreto $n^{\circ}$. 6/2020, publicado em 18 de março de 2020, em estado de calamidade pública, em decorrência da Pandemia da COVID-19. Decorrente dessa legislação, as medidas de isolamento para controlar o contágio da COVID-19, restringiram a oferta de aulas presenciais na rede de ensino pública e privada ou a proibição em todo o território nacional. Assim, novas orientações foram adotadas pelos entes federativos para conviver com essa imposição sanitária, o que foi tomado como Ensino Remoto Emergencial (ERE), ante a impossibilidade da presença da vida nas escolas. Sobre isso, trataremos na seção seguinte.

\section{Estratégias para implementação do Ensino Remoto Emergencial como alternativa para validar o direito à matrícula}

Em produção do ano de 2020, relativa à problematização decorrente do impacto da COVID-19 nos cursos de licenciatura, Souza e Ferreira (2020) debruçaram-se em perspectivar alternativas para composição dos currículos dos cursos de licenciatura, por meio de adoção de Ensino Remoto Emergencial, expressando a seguinte indagação: 
Nessa intenção, pergunta-se: é possível a oferta do estágio remoto pelos cursos de licenciatura, priorizando-se a vivência no campo de estágio, a sala de aula da educação básica? A tríade professor formador/professor supervisor/ estagiário é passível de modalizações nesse contexto de formação? Os sentidos atribuídos à profissionalização pelos licenciandos podem ser reverberados nas proposições e atividades para suplementação do estágio indicadas pelas instituições? Nesse interim, este texto organiza-se em um recorte acerca do estágio supervisionado e no nosso juízo de sua composição por meio do ensino remoto, para resguardar a vivência no espaço virtual de aprendizagem e de formação. (SOUZA; FERREIRA, 2020, p. 4).

Mesma problematização é circunscrita à educação básica, o que nos mobiliza a entrelaçar o direito à matrícula como percurso de aprendizagens e, consequentemente, terminalidade de um ano ou série escolar, ou curso.

Considerando dados do último Censo escolar (BRASIL, 2019), estima-se que desde março de 2020, cerca de 48 milhões de estudantes deixaram de frequentar as atividades presenciais, como forma de prevenção à propagação do novo coronavírus. Frente a essa realidade, impõe-se aos órgãos gestores replanejamento educacional e adoção de medidas estratégicas para definição de protocolos de retomadas às aulas, quer na forma presencial ou remota $^{6}$, bem como a avaliação sobre os percursos de aprendizagem dos estudantes, recuperando-se etapas de escolarização.

O Conselho Nacional de Educação (CNE), por meio do Parecer nº 05/2020 (BRASIL, 2020b) indica a adoção de um continuum de duas séries ou anos escolares, observadas as diretrizes nacionais, a Base Nacional Comum Curricular (BNCC) e as normas do respectivo sistema de ensino, considerando-se, para a oferta de atividades escolares não presenciais para compor a carga horária anual, que os estabelecimentos assegurem o acesso aos meios necessários para tal. Porém, a adoção de atividades não presenciais para compor a carga horária na Educação Básica deve ser tomada com cautela, porque envolve, além das condições de acesso dos estudantes e professores, a reelaboração dos projetos pedagógicos, a adequação metodológica, bem como a transposição de conteúdos escolares.

A Lei 14.040/2020 (BRASIL, 2020c) estabelece a dispensa pelos estabelecimentos de educação básica e superior, em caráter excepcional, da obrigatoriedade do mínimo dos dias de efetivo trabalho escolar e acadêmico, sem que a carga horária mínima anual seja alterada e observada as normas editadas pelos sistemas de ensino. Assim, os estabelecimentos de ensino

\footnotetext{
${ }^{6}$ Alves (2020, p. 352), refere à educação remota como sendo "práticas pedagógicas mediadas por plataformas digitais, como aplicativos com os conteúdos, tarefas, notificações e/ou plataformas síncronas e assíncronas como o Teams (Microsoft), Google Class, Google Meet, Zoom [...]". Segundo Alves (2020, p. 358), "educação remota predomina uma adaptação temporária das metodologias utilizadas no regime presencial, com as aulas, sendo realizadas nos mesmos horários e com os professores responsáveis pelas disciplinas dos cursos presenciais".
} 
de educação básica, excepcionalmente, estão dispensados da obrigatoriedade de observância do mínimo de 200 dias de efetivo trabalho escolar, desde que cumprida a carga horária mínima anual de 800 horas para o ensino infantil e fundamental e 1.400 horas para o ensino médio, conforme disposto no inc. I, $\S 1^{\circ}$ do art. 24 e no inc. II do art. 31 da Lei n ${ }^{\circ}$. 9.394/1996, LDB.

A imposição de suspensão das aulas presenciais requereu que estados e municípios, por meio de seus órgãos legislativos ou reguladores, elaborassem normativas que resguardassem a oferta educacional e, consequentemente validação da matrícula, adotando-se o Ensino Remoto Emergencial, educação a distância ou outras alternativas que preservassem o distanciamento social, ou seja, a ausência de contato presencial nas escolas ${ }^{7}$.

Em consulta à página oficial do Conselho Nacional de Secretários de Educação $(\mathrm{CONSEd})^{8}$, encontramos, em síntese, a descrição da seguinte situação dos estados brasileiros, quanto à oferta e alternativas para regularização do ano letivo escolar:

Quadro 1: Monitoramento das aulas presenciais por região do país.

Região Norte.

\begin{tabular}{|c|c|}
\hline $\mathrm{AC}$ & $\begin{array}{l}\text { O governo publicou o decreto } \mathrm{N}^{\circ} 7.225 \text { que autorizou o retorno das aulas presenciais em instituições } \\
\text { públicas e privadas desde o dia } 16 \text { de novembro. Retomada das aulas e demais atividades será opcional } \\
\text { para as instituições e unidades de ensino. Suspensão das aulas presenciais por tempo indeterminado. }\end{array}$ \\
\hline AM & Aulas em Manaus retornaram, mas a Rede Estadual no interior segue sem previsão de retorno. \\
\hline PA & As aulas presenciais na rede pública estadual de ensino só retornarão no início de 2021. \\
\hline RO & Suspensão das aulas presenciais por tempo indeterminado. \\
\hline $\mathrm{RR}$ & $\begin{array}{l}\text { Suspensão das aulas presenciais por tempo indeterminado / O estado segue com Ensino Remoto até } 10 \\
\text { de dezembro de } 2020 \text {, quando haverá suspensão do ano letivo / Houve antecipação do recesso escolar } \\
\text { entre } 17 \text { a } 31 \text { de março / No dia } 6 \text { de abril, teve início o oferecimento de aulas não presenciais/ dia } 1^{\circ} \\
\text { de setembro suspensão das atividades não presenciais na rede estadual de ensino até } 30.09 \text { - Portaria } \\
N^{\circ} 1123 / 2020 \text {. }\end{array}$ \\
\hline $\mathrm{AP}$ & Aulas presenciais apenas serão retomadas em 2021. \\
\hline \multicolumn{2}{|r|}{ Região Nordeste. } \\
\hline AL & $\begin{array}{l}\text { No Estado foi publicado um protocolo de orientação à gestão escolar para o retorno seguro das } \\
\text { atividades presenciais na rede estadual. Mas ainda não tem previsão de retorno. }\end{array}$ \\
\hline BA & Suspensão das aulas até 02 de dezembro. Não há data marcada para retorno \\
\hline $\mathrm{CE}$ & $\begin{array}{l}\text { A Secretaria da Educação está realizando reuniões, visitas e construindo um diálogo para decidir a } \\
\text { melhor data de retorno ao presencial. }\end{array}$ \\
\hline PB & Suspensão das aulas presencias por tempo indeterminado. \\
\hline $\mathrm{PE}$ & $\begin{array}{l}\text { O Estado teve retorno do Ensino Superior, Cursos Livres e Escolas Privadas. A Rede Pública iniciou o } \\
\text { processo de retomada no Ensino Médio em três etapas no dia } 21 \text { de outubro com os terceiros anos } \\
\text { Ensino Fundamental e Educação Infantil continuam com aulas suspensas e sem definição de data. }\end{array}$ \\
\hline PI & $\begin{array}{l}\text { No Estado retornaram às salas de aula estudantes do } 3^{\circ} \text { ano do ensino médio, VII etapa EJA e alunos } \\
\text { dos preparatórios para o Enem. / Previsão de retorno às aulas presenciais em } 19 \text { de outubro / Protocolo } \\
\text { em construção com instituições ligadas à Educação no estado (DECRETO } 18.966,30 \text { ABRIL 2020) / } \\
\text { Houve antecipação do recesso escolar entre } 17 \text { e } 31 \text { de março / Secretaria criou comitê para elaborar } \\
\text { um documento com orientações sobre o início das aulas remotas, marcadas para começar em } 6 \text { de abril. }\end{array}$ \\
\hline RN & $\begin{array}{l}\text { O Governo do Estado anunciou que as aulas presenciais serão retomadas em 2021. O ano letivo de } \\
2020 \text { será concluído de forma não presencial. }\end{array}$ \\
\hline MA & $\begin{array}{l}\text { As aulas presenciais nas escolas da Rede Pública Estadual continuam suspensas e o Estado segue com } \\
\text { ações para fortalecimento do ensino remoto em todas regionais. }\end{array}$ \\
\hline
\end{tabular}

\footnotetext{
${ }^{7}$ Ver Bermúdez (2021).

${ }^{8}$ https://consed.info/prazos/
} 


\begin{tabular}{|c|c|}
\hline SE & $\begin{array}{l}\text { rede estadual retornou com as aulas presenciais no dia } 17 \text { de novembro para o } 3^{\circ} \text { ano do ensino } \\
\text { édio, EJA EM e Educação profissional concluinte. }\end{array}$ \\
\hline \multicolumn{2}{|r|}{ Região Centro-Oeste. } \\
\hline $\mathrm{DF}$ & $\begin{array}{l}\text { O ano letivo de } 2020 \text { vai até } 28 \text { de janeiro de } 2021 \text {, de forma remota. Ano letivo será retomado em } 8 \\
\text { de março. A forma de retomada das atividades, ou seja, presencial ou híbrida, vai depender da situação } \\
\text { da pandemia no DF. As atividades remotas estão acontecendo pela plataforma Google Sala de Aula. } \\
\text { Estudantes sem acesso recebem material impresso. }\end{array}$ \\
\hline GO & Suspensão das aulas presenciais por tempo indeterminado. \\
\hline MS & $\begin{array}{l}\text { Prorrogação da suspensão das aulas presenciais até } 18 \text { de dezembro, concluindo o ano letivo de } 2020 \\
\text { remotamente. }\end{array}$ \\
\hline MT & Não haverá retorno das aulas presenciais este ano. \\
\hline TO & $\begin{array}{l}\text { De acordo com o último decreto governamental, de } 29 \text { de outubro, as aulas presenciais seguem } \\
\text { suspensas em todo o território do Tocantins, exceto para a etapa final da educação básica (ensino médio) } \\
\text { e para o ensino superior. Nestes últimos casos, as instituições de ensino devem se adequar ao Protocolo } \\
\text { de Segurança em Saúde, elaborado e publicado em conjunto entre as secretarias de Educação e de } \\
\text { Saúde, e pela Universidade Estadual do Tocantins (Unitins). }\end{array}$ \\
\hline \multicolumn{2}{|r|}{ Região Sudeste. } \\
\hline ES & $\begin{array}{l}\text { Aulas presenciais suspensas desde o dia } 16 \text { de novembro nos municípios de Vitória, Cariacica, Viana, } \\
\text { Ecoporanga e Barra de São Francisco, pelo fato dessas cidades terem passado para o risco moderado./ } \\
\text { As aulas presenciais das escolas da Rede Estadual retornaram no dia } 13 \text { de outubro, começando pelo } \\
\text { Ensino Médio, Educação de Jovens e Adultos (EJA) e Educação Profissional, seguido pelo } \\
\text { Fundamental } 2 \text { e, por último, Fundamental 1, com intervalo de } 15 \text { dias entre uma etapa e outra, após a } \\
\text { data de retorno de cada etapa, em regime de revezamento. }\end{array}$ \\
\hline MG & $\begin{array}{l}\text { O processo para a retomada das atividades escolares presenciais na rede pública estadual está suspenso, } \\
\text { não havendo uma data prevista para o retorno presencial dos estudantes às escolas estaduais. A } \\
\text { Secretaria de Estado de Educação segue ofertando aos alunos da rede o Regime de Estudo não } \\
\text { Presencial para a continuidade do processo de ensino e aprendizagem. }\end{array}$ \\
\hline RJ & $\begin{array}{l}\text { Aulas presenciais somente para os alunos que estão em terminalidade na Educação Básica ( } 3^{\text {a }} \text { série do } \\
\text { Ensino Médio, nas modalidades regular, técnico e de Educação de Jovens e Adultos - EJA - Módulo } \\
\text { IV). Os estudantes também podem escolher por seguir os estudos remotamente. Para as demais séries, } \\
\text { aulas presenciais previstas somente em 2021. Os colégios localizados em municípios que não } \\
\text { autorizaram a flexibilização das regras do isolamento social ou estiverem na classificação laranja de } \\
\text { contágio deverão continuar com atividades exclusivamente remotas. }\end{array}$ \\
\hline SP & $\begin{array}{l}\text { Desde o dia 8/9/2020, as escolas da rede estadual de São Paulo estão autorizadas pelo Governo do } \\
\text { Estado a retomar as atividades presenciais para recuperação e acolhimento, de forma gradual, } \\
\text { respeitando os protocolos de segurança. Para retomarem as atividades presenciais, as unidades } \\
\text { escolares precisam estar localizadas em áreas classificadas por pelo menos } 28 \text { dias consecutivos na fase } \\
\text { amarela do Plano São Paulo. As escolas estaduais que retornarem poderão receber, no máximo, } 20 \% \\
\text { dos alunos por dia, independente da etapa do ensino. Já as redes municipais e privadas devem seguir o } \\
\text { decreto do governo do estado que prevê o limite de } 35 \% \text { para educação infantil e anos iniciais do ensino } \\
\text { fundamental, e } 20 \% \text { para anos finais do ensino fundamental e ensino médio.. }\end{array}$ \\
\hline \multicolumn{2}{|r|}{ Região Sul. } \\
\hline PR & $\begin{array}{l}\text { Aulas extracurriculares presenciais liberadas para todo o estado (rede municipal, rede estadual e } \\
\text { particulares). Os colégios retomam o calendário extracurricular de acordo com a adesão dos pais dos } \\
\text { alunos. Ainda não há previsão para o retorno das aulas curriculares presenciais. }\end{array}$ \\
\hline $\mathrm{RS}$ & $\begin{array}{l}\text { Ensino Médio e Ensino Técnico: retornou dia } 20 \text { de outubro; Ensino Fundamental - Anos Finais: } \\
\text { retornou dia } 28 \text { de outubro; Ensino Fundamental - Anos Iniciais: a partir de } 12 \text { de novembro. }\end{array}$ \\
\hline SC & $\begin{array}{l}\text { Apenas aulas de reforço presencial, mas a obrigatoriedade é de atividades remotas até o fim do ano. O } \\
\text { prazo de suspensão de aulas presenciais que vigorava por decreto desde } 19 \text { de março expirou em } 12 \text { de } \\
\text { outubro e duas novas portarias estaduais ( } 750 \text { e } 778 \text { ), estabelecem as regras para retomada imediata de } \\
\text { atividades de acordo com o Plano Estadual de Contingência para a Educação (PlanCon Edu). As } \\
\text { atividades nas regiões com risco alto estão retomando de forma escalonada desde o dia } 19 \text { de outubro. }\end{array}$ \\
\hline
\end{tabular}

Fonte: https://consed.info/prazos.

O quadro 01 mostra as possibilidades de garantir a concretização da matrícula em diversos estados brasileiros que vai desde a adoção do ERE até a suspensão total para retorno 
no ano de 2021. Mesmo se tratando de regiões diferentes, percebemos que as alternativas se assemelham, pois a Pandemia nos deixou poucas opções e estas sinalizadas são as mais viáveis 9 .

Mostra ainda que o esvaziamento necessário da estrutura física da escola nos obrigou a reinventar novas estratégias de efetivar o direito a matrícula, o acesso e a permanência. Essa pandemia nos mostrou que, por mais difícil que seja a efetivação dos direitos em tempos de isolamento e incerteza, o direito à educação continua latente, portanto, viabilidades precisam ser pensadas para atendê-lo.

$\mathrm{Na}$ figura 1 mostramos a perspectiva de retomada das atividades escolares nas redes estaduais de educação em 2021.

Figura 1: Mapa de previsões de retomada das atividades escolares nas redes estaduais em 2021.

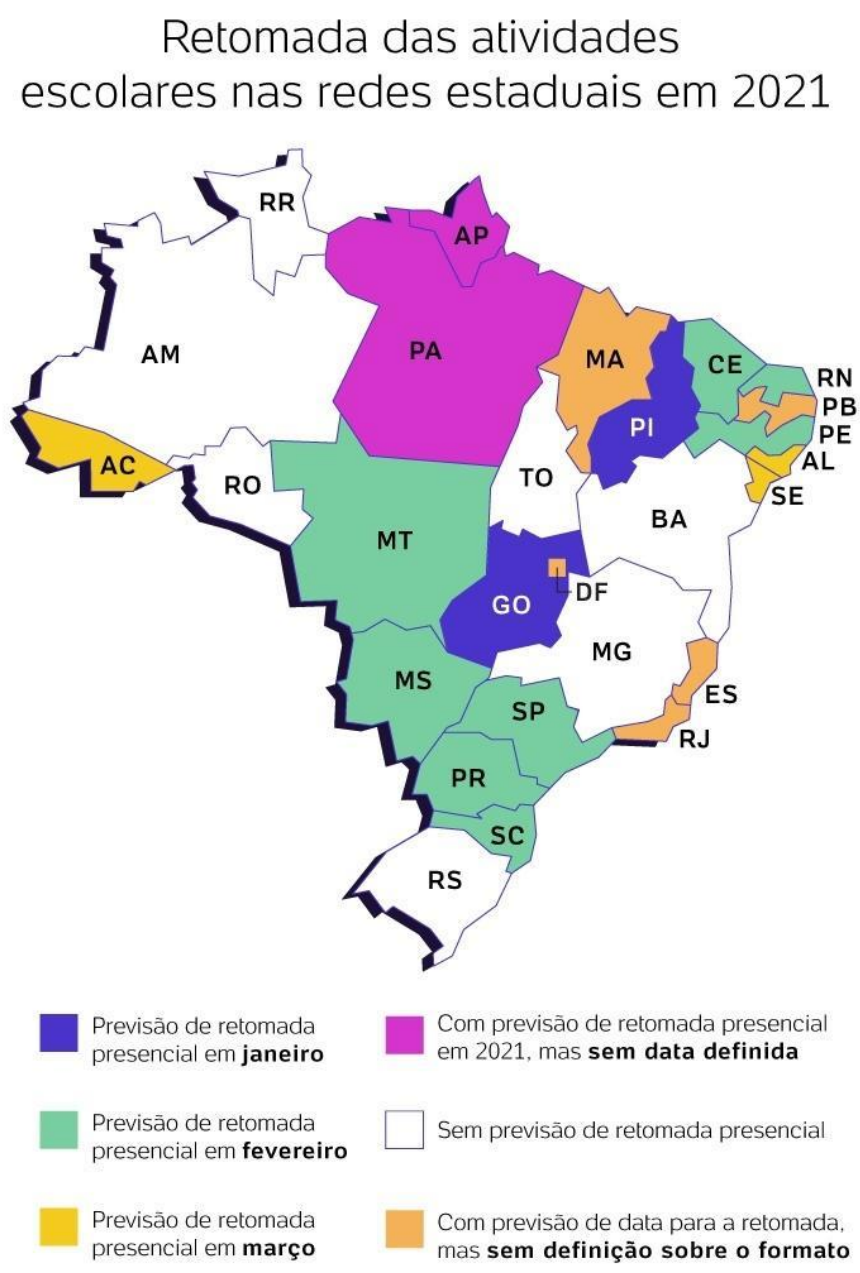

Fonte: Secretarias estaduais de educação

Fonte: Bermúdez (2021).

\footnotetext{
${ }^{9}$ Ver outros estudos como: Arruda (2020); Ribeiro Júnior et al. (2020); Ferraz, Ferreira e Ferraz (2021).
} 
Assim, surgem como alternativas:

- Continuum do calendário letivo 2020/2021;

- Oferta de ensino hibrido em que considera aulas não presenciais, tomada como remotas, por meio de plataformas digitais e as aulas presenciais;

- Revezamento de turmas com dos grupos de estudantes, alternando diariamente ou semanalmente;

- Adoção de plataforma com conteúdos para os estudantes;

- Celebração de parceria com canais aberto de TV para oferecer teleaulas;

- Adoção de Regime Especial de Atividades Escolares Não Presenciais;

- Adoção de logística para a entrega de material pedagógico, bem como merenda escolar, denominados como kit alimentar.

Para os estudantes concluintes do ensino médio, encontram-se proposições para que se possam matricularem-se no ano subsequente para estudos suplementares, contudo, com os calendários de exames e vestibulares para ingresso na Educação superior, há orientação para que, de forma diferenciada de resgate do ano letivo, esse público possa realizar os exames de certificação, como umas das possibilidades de conclusão do ensino médio. Segundo Paiva (2020, p. 64):

\footnotetext{
No Brasil, as soluções adotadas variaram de acordo com as condições de cada estado ou município. Não podemos ignorar que, em alguns casos, o que foi feito não pode ser chamado de ensino. Um exemplo foi a entrega de material impresso nas casas dos alunos, como aconteceu em alguns municípios. Apesar de louvável, isso não poderia ser chamado de ensino, pois não houve nenhum tipo de interação entre alunos e professores e nem processos de avaliação. Se se transfere para a família a responsabilidade de trabalhar o conteúdo com seus filhos e, ainda, se os responsáveis por esses alunos aceitam esse desafio, o que temos na verdade é educação domiciliar ou homeschooling, e não EaD ou ERE.
}

A educação como direito não se exclui, neste momento de Pandemia da COVID-19. Neste momento de emergência é sabido que as populações mais pobres sofrerão as consequências mais pesadas econômicas e sociais, pois, é fato que a pandemia intensificou as desigualdades sociais, problema já existente no cenário brasileiro O lugar público da escola, a convivência com a diversidade e a experiência compartilhada devem ser resguardados como norte para a própria sobrevivência das escolas e isso, ainda, não é possível de reiniciar.

A COVID-19 entrou no nosso sistema educacional no ano de 2020 e, mesmo com a vacina, perdurará os seus efeitos nos anos subsequentes. Apesar de alguns órgãos educacionais, com maior ou menor presteza, terem agindo iniciando o ensino remoto ou disponibilizando 
materiais e recursos educacionais não presenciais, como videoaulas, aulas gravadas, mensagens trocadas por aplicativos, grupos de whatsApp, facebook, etc., grande contingente de estudantes não foi atendido e teve o seu vínculo escolar suspenso, por um período superior a um ano letivo.

$\mathrm{Na}$ rede privada de ensino, o Ambiente Virtual de Aprendizagem (AVA) foi se realizando aos poucos, e, a maioria das escolas desse sistema concluiu o ano letivo. Por sua vez, os estabelecimentos públicos, ora projetam o continuиm de ano letivo, ora define por medidas de certificação atrelados aos exames nacionais.

Ao término do ano de 2020, muitos dos Estados e municípios brasileiros permanecem sem a oferta do ensino remoto e mesmo aqueles que já definiram a data do início da retomada das atividades escolares, quer ensino remoto ou hibrido, enfrentam os desafios de adotar medidas de segurança sanitária com a contínua propagação do vírus, o que determina a dilatação de novos prazos, redundando na conclusão do ano civil sem atendimento do calendário letivo escolar.

\section{Um passeio pelo Estado da Bahia}

Em matéria publicada no portal UOL “[...] os estados do Amazonas, Bahia, Minas Gerais, Rondônia e Roraima não há, até o momento, uma previsão ou definição para a volta das atividades presenciais nas redes públicas estaduais, e as atividades letivas devem ser retomadas de maneira remota em 2021" (BERMUDEZ, 2021, s/p).

Tomaremos, movidas pelo pertencimento institucional em instituições baianas, como docentes e pesquisadoras, o cenário o Estado da Bahia. Assim, em documento ${ }^{10}$ encontra-se orientação para a continuidade dos estudos no domicílio, visto que o Governo do Estado publicou no Diário Oficial, os Decretos No 19.529 e 19.549 de 16 e 18 de março de 2020, que regulamentam as medidas temporárias para o enfrentamento da emergência de saúde pública, sendo uma dessas medidas a suspensão das aulas presenciais que, por meio de sucessivos decretos tem sido renovada, tanto para a rede estadual, como municipais e particulares de ensino, em todos os municípios.

Assim, ante a impossibilidade de se adotar todas as diretrizes sanitárias que devem ser observadas para retorno presencial, bem como as regras estabelecidas pelos sistemas de ensino para a oferta do ensino remoto emergencial, o documento orienta "pelas atividades, via Plano

\footnotetext{
${ }^{10}$ Trata-se do Documento orientador dos planos de estudo para ação emergencial durante a vigência dos decretos
} $\mathrm{n}^{\mathrm{o}} 19.529 / 20$ e 19.549/20 aqui analisado através da carta da ANFOPE. 
Ester Maria de Figueiredo Souza | Lúcia Gracia Ferreira

de Estudo e/ou portais educacionais, para os estudantes da Rede Estadual de Ensino, vinculados às Unidades Escolares de toda a Bahia" (ANFOPE, 2020, p. 2), como se transcreve:

\subsection{Geral}

- Orientar atividades, via Plano de Estudo e/ou portais educacionais, para os estudantes da Rede Estadual de Ensino, vinculados às Unidades Escolares de toda a Bahia.

\subsection{Específicos}

- Possibilitar a continuidade dos estudos e do processo formativo dos estudantes das escolas da rede pública estadual.

- $\quad$ Disponibilizar modelo de Plano de Estudo e indicações de portais educacionais, para minimizar a interrupção do processo de aprendizagem durante a suspensão temporária das aulas (ANFOPE, 2020, p. 2).

Nesse sentido, optou-se pela adoção de Planos de Estudo, apostando na autonomia do estudante, para dar conta de seu percurso de aprendizagem, principalmente, para o público de estudantes do ensino médio:

O Plano de Estudo é uma estratégia pedagógica utilizada por estudantes e/ou candidatos a vagas de vestibulares, do Exame Nacional do Ensino Médio (ENEM) e ou concursos públicos que necessitam de uma organização sistemática para a realização de estudos dos conteúdos de interesse, dentro do tempo disponível do interessado (ANFOPE, 2020, p. 3).

No âmbito da competência estadual a opção foi pela manutenção da continuidade dos estudos:

[...] compete à Secretaria da Educação do Estado da Bahia, apresentar sugestões de atividades educacionais e pedagógicas para os estudantes e professores da Rede Estadual de Ensino, para a manutenção da continuidade dos estudos e qualificação profissional, por meio de disponibilização de plataformas, cursos, Aplicativos (APP), games educacionais e demais conteúdos educacionais, gratuitos (ANFOPE, 2020, p. 3).

O saldo do ano de 2020 confirma que, para os estabelecimentos públicos, o direito à matrícula foi protelado para anos subsequentes. Já as escolas particulares adequaram os seus currículos para concluir o ano letivo.

Repensar estratégias e currículos para reabrir as escolas ocupou grande parte do planejamento das gestões públicas, o que redundou na não adoção de atividades remotas emergenciais. O diagnóstico foi feito, contudo, como plano de ação, a operacionalização e a complexidade de universalizar o acesso e a formação do quadro de profissionais não foram suficientes para que medidas de atendimento ao ensino remoto fossem implementadas para validação da matrícula e do ano letivo. 
Em entrevista, o Secretário Estadual de Educação da Bahia, frisou o planejamento para retorno, na situação de redução do índice de transmissão, contudo devido ao aumento do número de infectados houve recuo. Também, que há a intenção de iniciar as aulas de forma híbrida, com calendário letivo de dois anos em um (2020-2021) deve ser planejado (VALVERDE, 2021).

Fato é, também, que nem todos os estudantes tem acesso ao ensino remoto. Faltaria equipamentos, condições de acesso, conhecimento sobre como manusear tais tecnologias ${ }^{11}$. Ainda, conforme Paiva (2020):

Ensino Remoto Emergencial (ERE) como uma mudança temporária da entrega de instruções para um modo de entrega alternativo devido a circunstâncias de crise. Para eles, esse tipo de abordagem envolve o uso de soluções de ensino totalmente remotas para a instrução ou a educação que, de outra forma, seriam ministradas presencialmente ou como cursos combinados ou híbridos, e que retornarão a esse formato assim que a crise ou emergência tiver diminuído. (PAIVA, 2020, p. 62).

A precarização das condições de infraestrutura de acesso ás tecnologias digitais associadas às necessidades de subsistências das famílias e dos estudantes das escolas públicas revelaram um enorme fosso sobre a garantia do direito educacional na Pandemia da COVID19. Em breve levantamento, todos os estabelecimentos privados informaram que cumpriram o que preconiza a Lei $\mathrm{n}^{\circ} .10 .040 / 2020$, enquanto a oferta nos estabelecimentos de ensino públicos não fora iniciada.

Contudo, constatamos que os responsáveis pela gestão educacional pública, mesmo assumindo a obrigatoriedade de matrícula 4 aos 17 anos e a necessidade da frequência escolar, reconheceram as imposições da pandemia e as circunstâncias para a oferta da educação escolar como impossibilidades no cenário remoto.

Por outro lado, as instituições privadas parcializaram o atendimento e facultaram o cancelamento da matrícula na educação infantil, ante a impossibilidade de modalizarem os projetos pedagógicos e as atividades curriculares para o ensino remoto ou hibrido. Situação diversa ao ensino fundamental e médio, em que, após um período de suspensão das aulas, adotaram-se medidas para realizar o ensino híbrido, emergencial no domicílio dos estudantes.

Adotando tratamento diferenciado para a terceira série do ensino médio, o Estado da Bahia, por meio da Portaria $n^{\circ}$ 985/2020, em caráter excepcional, em decorrência da situação de emergência de saúde pública, definiu regras de aproveitamento de estudos para fins de conclusão do Ensino Médio, em todas as ofertas e modalidades do sistema estadual de ensino,

${ }^{11}$ Ver Arruda (2020); Pretto, Bonilla e Sena (2020); Santos (2020). 
para o ano letivo de 2020, determinando o escore de aproveitamento em cada área de conhecimento e na redação, para lograr a certificação no ensino médio. Assim:

Art. $2^{\circ}$ Aproveitamento de estudos é o procedimento que as escolas e as unidades certificadoras adotam para compor o resultado final de um curso ou etapa de ensino, por meio dos resultados alcançados em exames, histórico escolar, certificações e outros meios formais.

$\S 1^{\circ} \mathrm{O}$ aproveitamento de estudos valida os saberes e conhecimentos dos estudantes obtidos por meios formais, de modo integral ou complementar.

$\S 2^{\circ}$ São considerados para fins de aproveitamento de estudos no sistema estadual de ensino, em 2020, para os estudantes concluintes do Ensino Médio, os resultados obtidos:

I) No Exame Nacional do Ensino Médio - ENEM;

II) No Exame Nacional para Certificação de Competências de Jovens e Adultos - ENCCEJA;

III) Nos exames de certificação aplicados pela Comissão Permanente de Avaliação - CPA;

IV) Nas atividades com características de terminalidade desenvolvidas pelas Unidades Escolares da rede estadual de ensino, sob coordenação da SEC.

$\S 3^{\circ} \mathrm{O}$ aproveitamento de estudos não é obrigatório, cabendo ao estudante interessado manifestar pessoalmente ou através do seu responsável legal essa opção, na secretaria escolar, dentro dos prazos estipulados pela SEC.

$\S 4^{\circ} \mathrm{O}$ estudante continuará regularmente matriculado, devendo dar continuidade às atividades letivas, conforme o novo calendário escolar de 2020, até a conclusão do Ensino Médio ou quando da obtenção da sua aprovação, se for o caso, por aproveitamento de estudos ou certificação. (BAHIA, 2020).

Destaca-se a concepção de aproveitamento de estudos desvinculada da convivência na escola, ante a não validação de atividades curriculares constantes nos projetos pedagógicos e de dias letivos do calendário escolar. Pode-se requerer o aproveitamento de estudos, na rede estadual, somente aqueles que se inscreveram no ENEM. Considerando as condições socioeconômicas, há de se supor, em uma visão otimista, que essa parte corresponda a $50 \%$ do total de matrículas nesta série.

Além do ENEM, outros exames são considerados, como: o Exame Nacional para Certificação de Competências de Jovens e Adultos (ENCCEJA) e os exames de certificação aplicados pela Comissão Permanente de Avaliação (CPA), essa no âmbito Estadual, e, desde que se obtenha pontuação exigida, logra-se o resultado de aprovado.

Desde 2012 o ENEM oportuniza a inscrição de candidato, maior de 18 anos, para certificação de etapa. Candidato não é estudante, portando não se encontra no lastro do currículo escolar em curso e inscritos em exames de certificação tem como objetivo a regularização da vida escolar para a continuidade de estudos. 


\section{Considerações Finais}

Iniciamos nosso texto com a compreensão que os tempos da pandemia nos exigem respostas éticas para preservar direitos sociais e nossa condição de cidadania no mundo. Buscamos, ao interpretar as orientações acerca do direito à educação, cotejar informações para, como base no ordenamento legal, acompanhar estratégias de implementação do ensino remoto emergencial na Pandemia da COVID-19, como um extrato de ilustração do direito à educação por parte de estabelecimentos de ensino, tomando, para isso, informações públicas. $\mathrm{O}$ levantamento foi feito por meio de informações divulgadas em sites oficias de órgãos reguladores e executores da educação, como secretarias de educação e conselhos de educação.

Os muitos muros que separam a rede pública da rede particular de ensino são de nosso conhecimento e os riscos da interrupção da vida escolar serão sentidos nos percursos de desenvolvimento da aprendizagem do estudante, quer em menor ou maior grau, tanto no estabelecimento público - que não logrou a oferta remota, ou que iniciou tardiamente ante as circunstâncias materiais - como nos demais.

O desafio da garantia do direito à matrícula no ano 2020 estende-se ao ano subsequente e, na gestão pública, os impactos foram sentidos com mais intensidade, culminando-se, principalmente, no nono ano do ensino fundamental e na terceira série do ensino médio, por serem etapas de terminalidade escolar. Assim, aos estudantes, com o decurso do ano civil, tiveram negado conclusão de uma etapa escolar, restando-lhe, no amparo da lei, os exames de certificação.

Desse modo, conclui-se que a exigência da obrigatoriedade da matrícula, enquanto perdurar os efeitos da COVID-19, encontra-se em suspensão nos estabelecimentos públicos, pois, como medida preventiva de contaminação, foi relativizada, por um motivo de força maior e alheio à vontade do sistema de ensino.

\section{REFERENCIAS}

ALVES, Lynn. Educação remota: entre a ilusão e a realidade. Interfaces Científicas. Aracaju, v.8, n.3, p. 348-365, 2020. Disponível em: https://periodicos.set.edu.br/educacao/article/view/9251. Acesso em: 14 ago. 2020.

ANFOPE. Associação Nacional pela Formação dos Profissionais da Educação. Parecer sobre Documento orientador dos planos de estudo para ação emergencial durante a vigência dos decretos no 19.529/20 e 19.549/20. Salvador, 02 de abril de 2020. Disponível em: http://www.anfope.org.br/wp-content/uploads/2020/04/PARECER-ANFOPE-PLANOESTUDO-SEC-BA-PERANTE-COVID-19.pdf. Acesso em: 31 mai. 2020. 
ARROYO, Miguel G. Imagens quebradas: trajetórias e tempos de alunos e mestres. 4. ed. Petrópolis, RJ: Vozes, 2004.

ARRUDA, Eucídio Pimenta. Educação Remota Emergencial: elementos para políticas públicas na educação brasileira em tempos de Covid-19. Em Rede - Revista de Educação a Distância. Porto Alegre, R.S, v. 7, n. 1, 2020, p. 257-275. Disponível em:

<https://www.aunirede.org.br/revista/index.php/emrede/ article/view/621>. Acesso em mai. de 2020.

AZEVEDO, Mário Luiz Neves de. Igualdade e Equidade: qual é a medida da justiça social? Avaliação, Campinas; Sorocaba, SP, v. 18, n. 1, p. 129-150, mar. 2013. Disponível em: https://www.scielo.br/scielo.php?pid=S141440772013000100008\&script=sci_abstract\&tlng=pt. Acesso: 30 jan. 2020.

BERMÚDEZ, Ana Carla. Pelo menos 15 estados têm previsão de retomada presencial das aulas em 2021... UOL, São Paulo. 04/01/2021. Disponível em:

https://educacao.uol.com.br/noticias/2021/01/04/previsao-de-retomada-presencial-das-aulasem-

2021.htm\#: :text=Sem\%20previs\%C3\%A3o\%20de\%20retomada\%20presencial,de\%20manei ra\%20remota\%20em\%202021. Acesso em: 05 jan. 2021.

BRASIL. Constituição da República Federativa do Brasil: promulgada em 5 de outubro de 1988. Brasília, 1988. Disponível em:

http://www.planalto.gov.br/ccivil_03/constituicao/constituicao.htm. Acessado em: 08 ago. 2019.

Lei 8.069, de 13 julho de 1990. Dispõe sobre o Estatuto da Criança e do Adolescente e dá outras providências. Diário Oficial da União, Brasília, DF, 1990. Disponível em: http://www.planalto.gov.br/ccivil_03/leis/18069.htm\#: :text=LEI\%20N\%C2\%BA\%208.069\% 2C\%20DE\%2013\%20DE\%20JULHO\%20DE\%201990.\&text=Disp\%C3\%B5e\%20sobre\%20 o\%20Estatuto\%20da,Adolescente $\% 20 \mathrm{e} \% 20 \mathrm{~d} \% \mathrm{C} 3 \%$ A $1 \% 20$ outras $\% 20$ provid\%C3\%AAncias. \&text=Art., \%C3\%A0\%20crian\%C3\%A7a\%20e\%20ao\%20adolescente.\&text=Nos\%20casos $\% 20$ expressos\%20em\%20lei,e \%20um\%20anos\%20de\%20idade. Acesso em: 28 out. 2020.

Lei no 9.394, de 20 de dezembro de 1996. Estabelece as diretrizes e bases da educação nacional. Brasília, 1996. Disponível em:

http://www.planalto.gov.br/ccivil_03/leis/19394.htm. Acesso em: 08 mai. 2019.

Lei 11.114, de 16 de maio de 2005. Com o objetivo de tornar obrigatório o início do ensino fundamental aos seis anos de idade. Diário Oficial da União: seção 1, Brasília, DF, ano 142, n. 93, p. 1, 17 de maio de 2005. Disponível em:

https://pesquisa.in.gov.br/imprensa/jsp/visualiza/index.jsp?jornal=1\&pagina $=1 \&$ data $=17 / 05 / 2$ 005. Acesso em: 03 dez. 2019.

Lei 11.274, de 6 de fevereiro de 2006. Estabelece as diretrizes e bases da educação nacional, dispondo sobre a duração de 9 (nove) anos para o ensino fundamental, com matrícula obrigatória a partir dos 6 (seis) anos de idade. Diário Oficial da União: seção 1, Brasília, DF, ano 143, n. 27, p. 1-2, 7 fev. 2006. Disponível em:

https://pesquisa.in.gov.br/imprensa/jsp/visualiza/index.jsp?data=07/02/2006\&jornal=1\&pagin a=1\&totalArquivos=64. Acesso em: 13 jun. 2020. 
. Emenda Constitucional 59, 2009. Ato das Disposições Constitucionais Transitórias para reduzir, anualmente, a partir do exercício de 2009, o percentual da Desvinculação das Receitas da União incidente sobre os recursos destinados à manutenção e desenvolvimento do ensino. Diário Oficial da União: seção 1, Brasília, DF, ano 147, n. 216, p. 8, 12 nov. 2009. Disponível em:

https://pesquisa.in.gov.br/imprensa/jsp/visualiza/index.jsp?data=12/11/2009\&jornal=1\&pagin a=8\&totalArquivos=128. Acesso em: 13 jun. 2020.

Lei 12.796, de 4 de abril de 2013. Estabelece as diretrizes e bases da educação nacional, para dispor sobre a formação dos profissionais da educação e dar outras providências. Diário Oficial da União: seção 1, Brasília, DF, ano 150, n. 65, p. 1-2, 5 abr. 2013. Disponível em:

https://pesquisa.in.gov.br/imprensa/jsp/visualiza/index.jsp?jornal=1\&pagina $=1 \&$ data $=05 / 04 / 2$ 013. Acesso em: 13 ago. 2020.

. MEC. INSTITUTO NACIONAL DE ESTUDOS E PESQUISAS EDUCACIONAIS ANÍSIO TEIXEIRA. Censo Escolar 2019: Notas Estatísticas. Brasília, DF: INEP, 2019. Disponível em: https://www.gov.br/inep/pt-br/areas-de-atuacao/pesquisas-estatisticas-eindicadores/censo-escolar/resultados. Acesso em: 17 out. 2020.

Lei 14.113, de 25 de dezembro de 2020. Regulamenta o Fundo de Manutenção e Desenvolvimento da Educação Básica e de Valorização dos Profissionais da Educação (Fundeb), de que trata o art. 212-A da Constituição Federal; revoga dispositivos da Lei no 11.494, de 20 de junho de 2007; e dá outras providências. Diário Oficial da União: seção 1, edição 246-C. Brasília, DF. Disponível em: https://www.in.gov.br/en/web/dou/-/lei-n-14.113de-25-de-dezembro-de-2020-296390151. Acesso em: 01 jan. 2020. 2020a.

Ministério da Educação. Conselho Nacional de Educação. Parecer CNE/CP 5, de 28 de abril de 2020. Reorganização do Calendário Escolar e da possibilidade de cômputo de atividades não presenciais para fins de cumprimento da carga horária mínima anual, em razão da Pandemia da COVID-19. Brasília: DF, 2020. D.O.U. de 01/06/2020, Seção 1, Pág. 32.Disponível em: http://www.in.gov.br/en/web/dou/-/despacho-de-29-de-maio-de-2020259412931. Acesso em: 30 jun. 2020. 2020b.

Lei 14.040, de 18 de agosto de 2020. Estabelece normas educacionais excepcionais a serem adotadas durante o estado de calamidade pública. Diário Oficial da União: seção 1, Brasília, DF, ano 158, n. 159, p. 4, 19 ago. 2020. Disponível em: https://pesquisa.in.gov.br/imprensa/jsp/visualiza/index.jsp?data $=19 / 08 / 2020 \&$ jornal $=515 \& p a$ gina $=4 \&$ totalArquivos=116. Acesso em: 19 set. 2020. 2020c.

BAHIA. Portaria $\mathbf{N}^{\mathbf{0}} \mathbf{9 8 5} / \mathbf{2 0 2 0}$. Dispõe sobre as regras de aproveitamento de estudos para os concluintes do Ensino Médio, em todas as ofertas e modalidades integrantes do Sistema Estadual de Ensino da Bahia, em caráter excepcional, em decorrência da situação emergencial de saúde pública, de importância internacional, decorrente do Coronavírus. Diário Oficial do Estado da Bahia, 19 de dezembro de 2020. Ano CV - No 23.054.

FERRAZ, Rita de Cássia Souza Nascimento; FERREIRA, Lúcia Gracia; FERRAZ, Roselane Duarte. Educação em tempos de pandemia: consequências do enfrentamento e (re)aprendizagem do ato de ensinar. Revista Cocar. Edição Especial N.09/2021 p.1-19. 
FREIRE, Paulo. Educação como prática de liberdade. 23 ed. Rio de Janeiro: Paz e Terra, 1999.

Política e Educação. São Paulo: Cortez Editora, 7 ed. 2003.

. Educação e Mudança. Tradução de Lilian Lopes Martins. 39 ed. Rio de Janeiro/São Paulo: Paz e Terra, 2018.

MÉSZAROS, István. A educação para além do capital. São Paulo: Boitempo, 2005

PAIVA, Vera Lucia Menezes de Oliveira. Ensino remoto ou ensino a distância efeitos da pandemia. Estudos Universitários: revista de cultura, v. 37, n. 1 e 2, Dez. 2020. P. 58-70.

PIZZIO, Alex. Embates acerca da ideia de justiça social em relação a conflitos sociais e desigualdades. Revista de Administração Pública. Rio de Janeiro. v. 50, n. 3. p. 355-375, maio/jun. 2016. Disponível em: https://www.scielo.br/pdf/rap/v50n3/0034-7612-rap-50-0300355.pdf. Acesso: 10 jan. 2021.

PRETTO, Nelson de Luca; BONILLA, Maria Helena Silveira; SENA, Ivânia Paula Freitas de Souza. Educação em tempos de pandemia: reflexões sobre as implicações do isolamento físico imposto pela COVID-19. Salvador: Edição do Autor, 2020.

PUJOL, Leonardo. O desafio de matricular os filhos na escola pública - durante a pandemia. Desafios da educação. 06/07/2020. Disponível em:

https://desafiosdaeducacao.grupoa.com.br/matricular-filhos-escola-publica-pandemia/. Acesso: 23 set. 2020.

SANTOS, Boaventura de Sousa. A cruel pedagogia do vírus (Pandemia Capital). Boitempo Editorial. Edição do Kindle, 2020.

SOUZA, Ester Maria de Figueiredo; FERREIRA, Lúcia Gracia. Ensino remoto emergencial e o estágio supervisionado nos cursos de licenciatura no cenário da Pandemia COVID 19.

Revista Tempos e Espaços em Educação. v. 13, n. 32, p. 1-19. 2020. Disponível em: https://seer.ufs.br/index.php/revtee/article/view/14290. Acesso: 15 nov. 2020.

RIBEIRO JUNIOR, Manoel Cícero; FIGUEIREDO, Luciano Silva; OLIVEIRA, Dalila Coragem Alves de; PARENTE, Márcia Percília Moura; HOLANDA, Jeisy dos Santos. Ensino Remoto em tempos de Covid-19: aplicações e dificuldades de acesso nos estados do Piauí e Maranhão. BOLETIM DE CONJUNTURA (BOCA). Ano II, vol. 3, n. 9, Boa Vista, 2020. p. 107-126. Disponível em: https://revista.ufrr.br/boca/article/view/RiberoJunior. Acesso: 15 nov. 2020.

TREVISOL, Joviles Vitório; MAZZIONI, Lizeu. A universalização da Educação Básica no Brasil: um longo caminho. Roteiro, v. 43, n. esp, p. 13-46, 6 dez. 2018. Disponível em: https://portalperiodicos.unoesc.edu.br/roteiro/article/view/16482/pdf. Acesso: 15 nov. 2020.

VALVERDE, Fernando. 2020 não foi um ano perdido para a educação', diz Jerônimo Rodrigues. A TARDE. 06/01/2021. Disponível em: https://atarde.uol.com.br/bahia/noticias/2152777-2020-nao-foi-um-ano-perdido-para-aeducacao-diz-jeronimo- 
rodrigues\#: :text=Em\%20entrevista\%20ao\%20programa\%20Isso,andamento\%20poss\%C3\% ADveis\%20neste\%20ano\%20de. Acesso: 07 jan. 2021.

\section{SOBRE AS AUTORAS:}

\section{Ester Maria de Figueiredo Souza}

Doutora em Educação pela Universidade Federal da Bahia (UFBA). Pós-doutoradoo pela Universidade de Brasília (UNB). Professora Plena da Universidade Estadual do Sudoeste da Bahia (UESB), atuando nos cursos de Licenciatura em Letras, no Programa de Pós-graduação em Letras: Cultura, Educação e Linguagens, e no Programa de Pós-graduação em Educação. Grupo de Pesquisa Linguagem e Educação E-mail: efigueiredo@uesb.edu.br

iD https://orcid.org/0000-0001-5992-0184

\section{Lúcia Gracia Ferreira}

Doutora em Educação pela Universidade Federal de São Carlos (UFSCar). Pós-doutorado pela Universidade Federal da Bahia (UFBA) e Universidade Estadual do Sudoeste da Bahia (UESB). Professora da Universidade Federal do Recôncavo da Bahia (UFRB) e da Universidade Estadual do Sudoeste da Bahia-Itapetinga (UESB). Professora do Programa de Pós-Graduação em Educação da Universidade Federal da Bahia e da UESB. Grupo de Pesquisa e Estudos Pedagógicos/UESB e Docência, Currículo e Formação/UFRB. E-mail: lucia.trindade@uesb.edu.br (iD https://orcid.org/0000-0003-3655-9124

Recebido em: 12 de janeiro de 2021

Aprovado em: 28 de janeiro de 2021

Publicado em: 01 de fevereiro de 2021 